\title{
Percutaneous Gastrostomy for Ketogenic Diet Therapy in Glut1DS
}

\author{
Klepper $\mathbf{J}^{*}$ \\ Children's Hospital Aschaffenburg-Alzenau, Am \\ Hasenkopf 1, D-63739 Aschaffenburg, Germany \\ *Corresponding author: J oerg Klepper, Children's \\ Hospital Aschaffenburg-Alzenau, Am Hasenkopf 1, \\ D-63739 Aschaffenburg, Germany
}

Received: February 05, 2021; Accepted: March 06, 2021; Published: March 13, 2021

\section{Keywords} Adult

Glut1 Deficiency; Glut1DS; Ketogenic diet; PEG; Gastrostomy;

\section{Letter to the Editor}

Glut1 Deficiency Syndrome (Glut1DS) results from impaired glucose transport into brain and presents with seizures, movement abnormalities, and developmental deficits. The only effective treatment is a high-fat, carbohydrate-restricted ketogenic diet providing ketones as an alternative fuel to the brain. The potential of ketogenic diets has recently been discussed in your journal [1].

Here we report a 24 year old woman with very mild cognitive impairment, a mild movement disorder and epilepsy. Glut1DS was confirmed at the age of six years by hypoglycorrhachia and a heterozygous pathogenic de novo missense mutation in the SLC2A1 gene (Thr137lle). On a classical 3:1 ketogenic diet treatment she was seizure-free with significant improved endurance, cognitive and motor performance if blood ketones (3-hydroxy-butyrate) were above $2.0 \mathrm{mmol} / \mathrm{l}$. She experienced near continuous absence seizures and also dyskinetic movements if her ketones were below this threshold. However, despite achieving puberty at the age of 14 years, she had difficulties meeting her nutritional requirements because of persistent vomiting. All efforts to improve the tolerability of the ketogenic diet, as well as modifications of the diet, were unsuccessful. Her bone density and BMI continued to decrease and she developed more seizures and abnormal movements despite many nutritional manoeuvres. At a BMI of 15.2 a Percutaneous Gastrostomy (PEG) was suggested.
It took three years before she came to terms with this option and following insertion of a gastrostomy her BMI improved to 18 within four months and with no evidence of biochemical derangements as a consequence of her rapid weight gain. Two years following this she remains on a classical 2:1 ketogenic diet with ketones consistently above her threshold of $2.0 \mathrm{mmol} / \mathrm{l}$, normal biochemistry, an improving bone density and a stable BMI of 18.6. She feels that it was a good decision, improving her quality of life by taking some of the stress out of meals, providing an alternative route for the delivery of fluids, food and medication, tailored to her ongoing needs. She has experienced less in the way of ictal events or dyskinesias since this time.

A PEG is an established option in patients with feeding difficulties and severe cognitive impairment. It is, however, a difficult decision to suggest to a young, mildy impaired woman with high overall quality of life. Our patient, her caretakers, and the treating physicians felt very uneasy with this procedure. However, we felt that it was important to report that this measure improved the quality of life in our patient. We propose that in Glut1DS patients dependent on a ketogenic diet and a level of ketosis that otherwise that cannot be obtained, the option of a PEG should be offered early.

\section{Conflict of Interest}

Joerg Kleppera received speaker honoraria and travel costs from Nutricia GmbH, Erlangen, Germany and Vitaflo International LTD, Liverpool, UK.

\section{Ethical Compliance Statement}

We confirm that we have read the Journal's position on issues involved in ethical publication and affirm that this work is consistent with those guidelines.

\section{References}

1. Ludwig DS. The Ketogenic Diet: Evidence for Optimism but High-Quality Research Needed. J Nutr. 2020; 150: 1354-1359.

2. Klepper J. GLUT1 deficiency syndrome in clinical practice. Epilepsy Res. 2012; 100: 272-277.
Austin J Nutr Metab - Volume 8 Issue 1 - 2021

Submit your Manuscript | www.austinpublishinggroup.com

Klepper. (c) All rights are reserved 